\title{
Darbepoetin Alfa Increases Plasma N-acetyl-seryl-aspartyl-lysyl-proline Level in Kidney Transplant Recipient: A Case Report
}

\author{
Yosuke Suzuki $^{* 1}$, Fumihiko Katagiri ${ }^{2}$, Fuminori Sato $^{3}$, Yuhki Sato ${ }^{1}$, Hiromitsu Mimata $^{3}$ and Hiroki Itoh ${ }^{1}$ \\ ${ }^{1}$ Department of Clinical Pharmacy, Oita University Hospital, Japan \\ ${ }^{2}$ Laboratory of Clinical Biochemistry, Tokyo University of Pharmacy and Life Sciences, Japan \\ ${ }^{3}$ Department of Urology, Oita University, Japan
}

*Corresponding author: Yosuke Suzuki, Department of Clinical Pharmacy, Oita University Hospital, Hasama-machi, Oita 879-5593, Japan, Tel: +81-97-586-6113; Fax: +81-97-586-6119; E-mail: y-suzuki@oita-u.ac.jp

Rec date: Jul 12, 2014, Acc date: Oct 28, 2014, Pub date: Oct 30, 2014

Copyright: (C) 2014 Suzuki Y, et al. This is an open-access article distributed under the terms of the Creative Commons Attribution License, which permits unrestricted use, distribution, and reproduction in any medium, provided the original author and source are credited.

\begin{abstract}
We report a case of elevated plasma $\mathrm{N}$-acetyl-seryl-aspartyl-lysyl-proline (AcSDKP)-like immunoreactive substance (IS) level after multiple doses of a recombinant human erythropoietin (rHuEPO), darbepoetin alfa, in a 50 year-old Japanese female who underwent kidney transplantation. Plasma AcSDKP-IS levels showed a gradual decline after kidney transplantation. However, plasma AcSDKP-IS level showed a rapid rise on day 70, and remained at high levels for a period of time and then declined sharply on day 119. After maintaining relatively constant levels from day 119, plasma AcSDKP level showed a rapid rise again on day 168, and declined again on day 238. The two abrupt increases and subsequent sharp decreases of plasma AcSDKP-IS levels correlated temporally with the initiation and discontinuation of the two course of darbepoetin alfa. Although further detailed studies are necessary, administration of darbepoetin alfa may cause a marked increase in plasma AcSDKP level.
\end{abstract}

Keywords: $\quad \mathrm{N}$-acetyl-seryl-aspartyl-lysyl-proline; $\quad$ AcSDKP; Darbepoetin alfa; Recombinant human erythropoietin; Kidney transplantation

\section{Introduction}

$\mathrm{N}$-acetyl-seryl-aspartyl-lysyl-proline (AcSDKP) is an endogenous peptide released from its precursor (thymosin- $\beta 4$ ) by prolyl oligopeptidase (POP) [1,2]. AcSDKP is a natural inhibitor of pluripotent hematopoietic stem cell proliferation by preventing cells from entering $S$ phase from G1 of the cell cycle $[3,4]$, and is normally found in human plasma [5]. AcSDKP has been shown to suppress the proliferation of renal fibroblasts [6] and inhibit collagen deposition in cardiac fibroblasts in mice [7]. AcSDKP has also been shown to be a potent angiogenic factor [8,9] and it has been reported that AcSDKP levels were significantly increased in patients with cancer, such as hematologic malignancy [10] and papillary carcinoma [11]. Because AcSDKP is hydrolyzed by the $\mathrm{N}$-terminus active site of angiotensinconverting enzyme (ACE) [12,13] and partially eliminated in urine [14], its plasma level is a result of a complex balance between its production by POP, hydrolysis by ACE, and renal elimination. Thus, plasma AcSDKP levels have been shown to increase in patients with chronic renal failure $[15,16]$. Le Meur et al have studied the relation between AcSDKP levels and the weekly dose of recombinant human erythropoietin (rHuEPO) for the treatment of renal anemia [16]. They observed that dialysis patients required significantly more $\mathrm{rHuEPO}$ when their AcSDKP levels were higher, indicating an inhibitory effect of AcSDKP on hematopoiesis. However, it has been uncertain whether accumulated AcSDKP reflected inhibitory effect on hematopoiesis or rHuEPO simply had a potency increasing plasma AcSDKP levels.

We report a case of elevated plasma AcSDKP-like immunoreactive substance (IS) level after multiple administration of darbepoetin alfa,
rHuEPO, in a 50 years old Japanese female underwent kidney transplantation.

\section{Case}

The patient was diagnosed with chronic glomerulonephritis and received hemodialysis from March 1993. In January 2011, she underwent the cadaveric kidney transplantation in Oita university hospital. Hemodialysis was performed total of 8 times up to 16 days after the kidney transplantation, and then, hemodialysis was discontinued because the increase in urinary volume and the reduction in serum creatinine level were observed. She was treated using a triple-therapy immunosuppression protocol, associating a tacrolimus, mycophenolate mofetil and corticosteroid. Furthermore, she received an induction therapy with basiliximab. Dosage of tacrolimus was adjusted from the trough concentration in whole blood. After the kidney transplantation, absence of rejection was kept, so she left the hospital in day 32 after kidney transplantation and was followed as an outpatient.

Hemoglobin level was $11.6 \mathrm{~g} / \mathrm{dL}$ on the day of kidney transplantation. It showed a gradual decline after kidney transplantation and it was reduced to $9.3 \mathrm{~g} / \mathrm{dL}$ in day 42 after kidney transplantation. In addition, subjective symptoms such as wobble showed after discharge from a hospital. Iron deficiency was negative, thus darbepoetin alfa was administered subcutaneously from day 42 in $60 \mu \mathrm{g}$ per 1 or 2 weeks. After that, hemoglobin level rose progressively and rebounded to $12.4 \mathrm{~g} / \mathrm{dL}$ in day 112 due to effect of darbepoetin alfa, so administration of darbepoetin alfa was stopped for the last after administration in day 105. However, hemoglobin level reduced again after stopped, thus darbepoetin alfa was administered again from day 147 in $40 \mu \mathrm{g}$ per 1 or 2 weeks. And then, subjective symptoms improved, although hemoglobin level remained at approximately the 
same level, so darbepoetin alfa was stopped again for the last after administration in day 210 .

We measured plasma AcSDKP-IS level of this patient over time before and after kidney transplantation. This research was approved by the Institutional Review Board of Oita University Hospital. She received information about the scientific purpose of the research and gave written informed consent. Plasma AcSDKP-IS level was measured using an enzyme immunoassay [17].

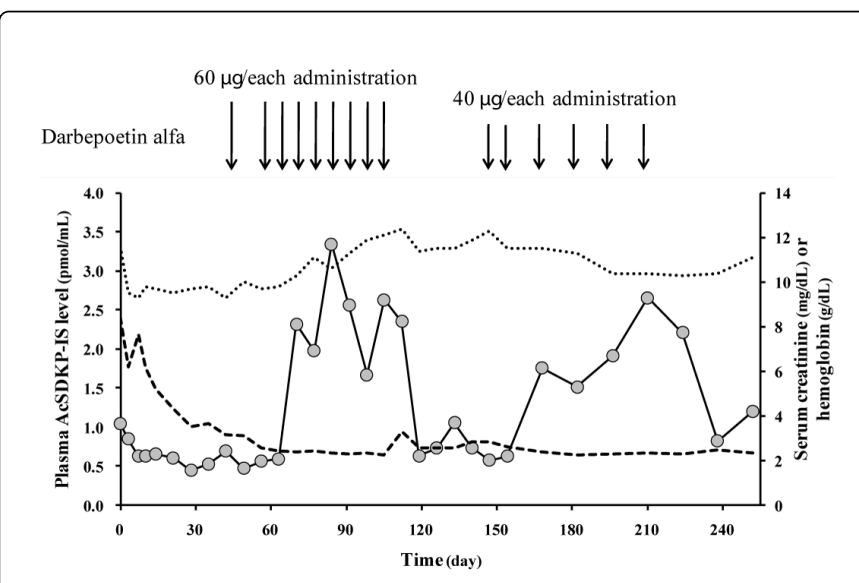

Figure 1: Transitions of levels of plasma AcSDKP-IS and serum creatinine after kidney transplantation. Gray points and solid line show the transition of plasma AcSDKP-IS level, the dashed line shows the transition of serum creatinine level, and dotted line shows the transition of hemoglobin level.

Transitions of levels of plasma AcSDKP-IS and serum creatinine after kidney transplantation are shown in (Figure 1). Plasma AcSDKPIS levels showed a gradual decline after kidney transplantation. This was assumed to be due to the acceleration of AcSDKP elimination into the urine with the improvement of kidney function after kidney transplantation [18]. However, plasma AcSDKP-IS level showed a rapid rise on day 70. Plasma AcSDKP-IS level remained at a high level for a while after that and descended on day 119. After constant transition from day 119, plasma AcSDKP level showed a rapid rise again on day 168 , and descended again on day 238 . On the other hand, serum creatinine level decreased spending 2 months after the kidney transplantation and showed almost constant transition after that.

\section{Discussion}

The clinical conditions of the patient remained unchanged during this period except for improvement in kidney function. The newlyadministered drug after kidney transplantation was only darbepoetin alfa except for the immunosuppressions. Furthermore, twice abrupt increases and subsequent decreases of plasma AcSDKP-IS levels were observed after the initiations and discontinuances of darbepoetin alfa, respectively. These suggest that elevation of plasma AcSDKP-IS level in this case may be invoked by darbepoetin alfa, and increased AcSDKP may inhibit elevation of hemoglobin level after second administration of darbepoetin alfa. Le Meur et al had reported that the uremic toxin-like effect of AcSDKP accumulated by the renal involvement stimulated dose escalation of rHuEPO [16]. In this case, adversely, administration of darbepoetin alfa may originate the increase of plasma AcSDKP level, although the mechanism is unknown. Recently, kidney protective effects and tumor progressions were reported as the novel effect of rHuEPO [19-23]. AcSDKP also has similar effects $[6,8,9]$, suggested that elevated plasma AcSDKP after administration of rHuEPO may be partially involved in the kidney protective effects and tumor progressions by $\mathrm{rHuEPO}$.

The abrupt increase of plasma AcSDKP level caused by darbepoetin alfa has been formulated from a theoretical point of view and, to the best of our knowledge, a case report of a transition of AcSDKP level after administration of $\mathrm{rHuEPO}$ has not been reported in the literature before. How darbepoetin alfa increases plasma AcSDKP level is unknown, so further detailed studies are necessary.

\section{Conclusion}

We demonstrated a close temporal relationship between increase in plasma AcSDKP level and darbepoetin alfa administration, and hypothesize an involvement of AcSDKP in the observed effects of rHuEPO. Although further detailed studies are necessary, elevated plasma AcSDKP after administration of $\mathrm{rHuEPO}$ may be partially involved in the observed roles of $\mathrm{rHuEPO}$ in reno-protection and tumor progression.

\section{References}

1. Guigon M, Bonnet D, Lemoine F, Kobari L, Parmentier C, et al. (1990) Inhibition of human bone marrow progenitors by the synthetic tetrapeptide AcSDKP. Exp Hematol 18: 1112-1115.

2. Cavasin MA, Rhaleb NE, Yang XP, Carretero OA (2004) Prolyl oligopeptidase is involved in release of the antifibrotic peptide Ac-SDKP. Hypertension 43: 1140-1145.

3. Bonnet D, Lemoine FM, Pontvert-Delucq S, Baillou C, Najman A, et al. (1993) Direct and reversible inhibitory effect of the tetrapeptide acetyl-NSer-Asp-Lys-Pro (Seraspenide) on the growth of human CD34+ subpopulations in response to growth factors. Blood 82: 3307-3314.

4. Wdzieczak-Bakala J, Fache MP, Lenfant M, Frindel E, Sainteny F (1990) AcSDKP, an inhibitor of CFU-S proliferation, is synthesized in mice under steady-state conditions and secreted by bone marrow in long-term culture. Leukemia 4: 235-237.

5. Pradelles P, Frobert Y, Créminon C, Liozon E, Massé A, et al. (1990) Negative regulator of pluripotent hematopoietic stem cell proliferation in human white blood cells and plasma as analysed by enzyme immunoassay. Biochem Biophys Res Commun 170: 986-993.

6. Iwamoto N, Xano HJ, Yoshioka T, Shiraga H, Nitta K, et al. (2000) Acetyl-seryl-aspartyl-lysyl-proline is a novel natural cell cycle regulator of renal cells. Life Sci 66: PL221-PL226.

7. Rhaleb NE, Peng H, Yang XP, Liu YH, Mehta D, et al. (2001) Long-term effect of N-acetyl-seryl-aspartyl-lysyl-proline on left ventricular collagen deposition in rats with 2-kidney, 1-clip hypertension. Circulation 103: 3136-3141.

8. Liu JM, Lawrence F, Kovacevic M, Bignon J, Papadimitriou E, et al. (2003) The tetrapeptide AcSDKP, an inhibitor of primitive hematopoietic cell proliferation, induces angiogenesis in vitro and in vivo. Blood 101: 3014-3020.

9. Wang D, Carretero OA, Yang XY, Rhaleb NE, Liu YH, et al. (2004) Nacetyl-seryl-aspartyl-lysyl-proline stimulates angiogenesis in vitro and in vivo. Am J Physiol Heart Circ Physiol 287: H2099-2105.

10. Liu JM, Gora-Tybor J, Grzybowska-Izydorczyk O, Bignon J, Robak T, et al. (2009) Elevated plasma levels of the angiogenic tetrapeptide acetyl-serasp-lys-pro are found in some patients with hematologic malignancies. Leuk Lymphoma 50: 2096-2097.

11. Kusinski M, Wdzieczak-Bakala J, Liu JM, Bignon J, Kuzdak K (2006) AcSDKP: a new potential marker of malignancy of the thyroid gland. Langenbecks Arch Surg 391: 9-12. 
Citation: Suzuki Y, Katagiri F, Sato F, Sato Y, Mimata H, et al. (2014) Darbepoetin Alfa Increases Plasma N-acetyl-seryl-aspartyl-lysyl-proline Level in Kidney Transplant Recipient: A Case Report. J Transplant Technol Res 4: 143. doi:10.4172/2161-0991.1000143

Page 3 of 3

12. Rieger KJ, Saez-Servent N, Papet MP, Wdzieczak-Bakala J, Morgat JL, et al. (1993) Involvement of human plasma angiotensin I-converting enzyme in the degradation of the haemoregulatory peptide $\mathrm{N}$-acetylseryl-aspartyl-lysyl-proline. Biochem J 296: 373-378.

13. Rousseau A, Michaud A, Chauvet MT, Lenfant M, Corvol P (1995) The hemoregulatory peptide $\mathrm{N}$-acetyl-Ser-Asp-Lys-Pro is a natural and specific substrate of the N-terminal active site of human angiotensinconverting enzyme. J Biol Chem 270: 3656-3661.

14. Azizi M, Ezan E, Reny JL, Wdzieczak-Bakala J, Gerineau V, et al. (1999) Renal and metabolic clearance of $\mathrm{N}$-acetyl-seryl-aspartyl-lysyl-proline (AcSDKP) during angiotensin-converting enzyme inhibition in humans. Hypertension 33: 879-886.

15. Le Meur Y, Aldigier JC, Praloran V (1998) Is plasma Ac-SDKP level a reliable marker of chronic angiotensin-converting enzyme inhibition in hypertensive patients? Hypertension 31: 1201-1202.

16. Le Meur Y, Lorgeot V, Comte L, Szelag JC, Aldigier JC, et al. (2001) Plasma levels and metabolism of AcSDKP in patients with chronic renal failure: relationship with erythropoietin requirements. Am J Kidney Dis 38: 510-517.

17. Suzuki Y, Itoh H, Katagiri F, Sato F, Kawasaki K, et al. (2012) Establishment and clinical application of a highly sensitive enzyme immunoassay for determination of $\mathrm{N}$-acetyl-seryl-aspartyl-lysyl-proline. J Pept Sci 18: 276-281.
18. Suzuki Y, Katagiri F, Sato F, Fujioka K, Sato Y, et al. (2014) Significant Decrease in Plasma N-Acetyl-seryl-aspartyl-lysyl-proline Level in Patients with End Stage Renal Disease after Kidney Transplantation. Biol Pharm Bull 37: 1075-1079.

19. Kasap B, Soylu A, Kuralay F, Sarioglu S, Kiray M, et al. (2008) Protective effect of Epo on oxidative renal injury in rats with cyclosporine nephrotoxicity. Pediatr Nephrol 23: 1991-1999.

20. Rjiba-Touati K, Boussema IA, Belarbia A, Achour A, Bacha H (2011) Protective effect of recombinant human erythropoietin against cisplatininduced oxidative stress and nephrotoxicity in rat kidney. Int J Toxicol 30: 510-517.

21. Miller CP, Lowe KA, Valliant-Saunders K, Kaiser JF, Mattern D, et al. (2009) Evaluating erythropoietin-associated tumor progression using archival tissues from a phase III clinical trial. Stem Cells 27: 2353-2361.

22. Welsch T, Zschäbitz S, Becker V, Giese T, Bergmann F, et al. (2011) Prognostic significance of erythropoietin in pancreatic adenocarcinoma. PLoS One 6: e23151.

23. Wang L, Li HG, Xia ZS, Wen JM, Lv J (2011) Prognostic significance of erythropoietin and erythropoietin receptor in gastric adenocarcinoma. World J Gastroenterol 17: 3933-3940. 